This Accepted Author Manuscript is copyrighted and published by Elsevier. It is posted here by agreement between Elsevier and University of Brasilia. Changes resulting from the publishing process - such as editing, corrections, structural formatting, and other quality control mechanisms - may not be reflected in this version of the text. The definitive version of the text was subsequently published in [Research in Veterinary Science, Volume 90, Issue 3, June 2011, Pages 404-411, doi:10.1016/j.rvsc.2010.07.007].You may download, copy and otherwise use the AAM for non-commercial purposes provided that your license is limited by the following restrictions:

(1) You may use this AAM for non-commercial purposes only under the terms of the CC-BY-NCND license.

(2) The integrity of the work and identification of the author, copyright owner, and publisher must be preserved in any copy.

(3) You must attribute this AAM in the following format: [agreed attribution language, including link to CC BY-NC-ND license + Digital Object Identifier link to the published journal article on Elsevier's ScienceDirect ${ }^{\circledR}$ platform].

Este Manuscrito do Autor Aceito para Publicação (AAM) é protegido por direitos autorais e publicado pela Elsevier. Ele esta disponível neste Repositório, por acordo entre a Elsevier e a Universidade de Brasília. As alterações decorrentes do processo de publicação - como a edição, correção, formatação estrutural, e outros mecanismos de controle de qualidade - não estão refletidas nesta versão do texto. A versão definitiva do texto foi posteriormente publicado em [Research in Veterinary Science, Volume 90, Número 3, Junho 2011, Pages 404-411, doi:10.1016/j.rvsc.2010.07.007]. Você pode baixar, copiar e utilizar de outra forma o AAM para fins não comerciais, desde que sua licença seja limitada pelas seguintes restrições:

(1) Você pode usar este AAM para fins não comerciais apenas sob os termos da licença CC- BYNC-ND.

(2) A integridade do trabalho e identificação do autor, detentor dos direitos autorais e editor deve ser preservado em qualquer cópia.

(3) Tem de atribuir este AAM no seguinte formato: [acordo na linguagem atribuída, incluindo o link para CC BY-NC-ND licença Digital + DOI do artigo publicado na revista Elsevier ScienceDirect ${ }^{\circledR}$ da plataforma]. 


\title{
In vitro development of primordial follicles after long-term culture of goat ovarian tissue
}

\author{
M.H.T. Matos \\ J.B. Bruno \\ R.M.P. Rocha \\ I.B. Lima-Verde \\ K.D.B. Santos \\ M.V.A. Saraiva \\ J.R.V. Silva \\ F.S. Martins \\ R.N. Chaves \\ S.N. Báo \\ J.R. Figueiredo
}

\begin{abstract}
This study aims to investigate the effects of follicle stimulating hormone (FSH) and fibroblast growth factor-2 (FGF-2) on the survival and growth of caprine preantral follicles. Ovarian tissues were cultured for $1,7,14,21$ or 28 days in medium supplemented with FSH (FSH-2d or FSH-7d, i.e., with replacement of the culture medium every 2 or 7 days, respectively) or FSH + FGF-2 (replacement of the medium every 2 days). Non-cultured (control) and cultured ovarian fragments were processed for histological and ultrastructural analysis. After 28 days of culture, the media supplemented with FSH-2d was the most effective in maintaining the percentage of normal follicles and in promoting follicular growth. Furthermore, both treatments with FSH increased the percentage of the primary follicles. However, ultrastructural studies did not confirm follicular integrity from 14 days of culture onward. In conclusion, culturing tissue for up to 7 days in medium containing FSH alone or combined with FGF-2 maintains caprine preantral follicle integrity and promotes their growth in vitro.
\end{abstract}

Keywords: Caprine; Primordial follicle; Long-term culture; FSH; FGF-2

\section{Introduction}

As primordial follicles form the largest population of follicles in the ovary, the development of a culture system that starts from this stage of growth could potentially produce mature oocytes and would significantly advance the use of reproductive technologies. In larger species, early follicular development follows a very lengthy and complex process. It has been estimated that primary follicles need approximately 120 days to grow into secondary follicles and that a longer time is needed for primordial follicles to develop into primary follicles (Gougeon, 1996). Therefore, an extended culture period may be required for a follicle to develop to the preovulatory stage. Few long-term in vitro culture studies have achieved follicular activation, i.e., the transition from primordial to primary follicles (ovine: Muruvi et al., 
2005; human: Otala et al., 2002 and Sadeu et al., 2006) or the development of antral follicles (bovine: Gutierrez et al., 2000; mouse: Mitchell et al., 2002). Recently, Gupta et al. (2008) produced buffalo embryos after the long-term culture of isolated large secondary follicles. Interestingly, in most of the in vitro culture systems, independent of the culture period, the medium has been totally or partially replaced by fresh medium every other day (Silva et al., 2004 and Muruvi et al., 2005).

Both intra- and extraovarian factors have been implicated in follicular activation (Fortune, 2003). Although FSH receptors are expressed in granulosa cells (O'Shaughnessy et al., 1996) from the primary follicle stage onward (Oktay et al., 1997), this hormone may act indirectly in the primordial follicles through paracrine factors secreted by larger follicles or stromal cells. Several in vitro studies have demonstrated that FSH promotes the in vitro growth of early caprine preantral follicles and antrum formation in different species after the in vitro culture of large secondary follicles (for a review, see van den Hurk and Zhao, 2005). Additionally, it is known that FSH inhibits apoptosis in preantral follicles that have been cultured in vitro (Roy and Treacy, 1993 and McGee et al., 1997). Recently, we demonstrated that FSH is essential for maintaining the morphological integrity of caprine primordial follicles that are enclosed in ovarian tissue and cultured for 7 days (Matos et al., 2007a).

One factor that is involved in paracrine signaling within the follicle is fibroblast growth factor-2 (FGF-2), which acts in cell differentiation and migration, as well as angiogenesis, in many tissues (Baird et al., 1986 and Gospodarowicz et al., 1986). It has been localized to ovarian follicles (Nilsson et al., 2001 and Ben-Haroush et al., 2005) and corpora lutea (Asakai et al., 1993), while FGF-2 receptors have been found in growing follicles (Wandji et al., 1992, Wandji et al., 1995 and Ben-Haroush et al., 2005). Some in vitro studies have demonstrated that FGF-2 promoted the growth of primordial and primary follicles (Nilsson et al., 2001), as well as the proliferation of granulosa and theca cells (Wandji et al., 1996). In goats, Matos et al. (2007b) showed that FGF-2 is able to activate primordial follicles after 5 days of culture, although follicle survival was not influenced by FGF-2 treatment.

With regard to an interaction between FSH and FGF-2, it has been suggested that FSH induces functional receptors for FGF-2 in rat granulosa cells and that FGF-2 may play a role in the process of granulosa cell differentiation under the influence of FSH (Shikone et al., 1992). We have demonstrated that an interaction between FSH and FGF-2 promoted caprine follicular activation and oocyte growth (Matos et al., 2007c) in a 7 days culture system. However, there are apparently no reports showing the effects of FSH alone or in association with FGF-2 on follicular activation and growth after the long-term culture of caprine ovarian tissue. Furthermore, no culture system has been reported that can maintain isolated caprine follicle 
integrity for longer than 14 days (Huamin and Yong, 2000). Additionally, it is not known if the interval between medium changes ( 2 or 7 days) influences follicular development.

The aims of the current study were to evaluate (1) the effects of FSH alone or in combination with FGF-2 on morphological integrity, activation and further growth after the long-term culture of caprine primordial follicles enclosed in ovarian tissue and (2) the effects of the interval between medium changes on the follicular integrity and development after in vitro culture.

\section{Materials and methods}

\subsection{Chemicals}

Unless mentioned otherwise, all of the reagents and chemicals used in the present study were purchased from Sigma Chemical Co. (St. Louis, USA). Porcine FSH was provided by Dr. J.F. Beckers (Liège, Belgium) and FGF-2 (basic, from bovine pituitary glands) was purchased from MP Biomedicals (OH, USA).

\subsection{Source of caprine ovarian tissue}

The ovaries $(n=8)$ from four adult (1-3 years old) non-pregnant mixed-breed goats were collected at a local slaughterhouse (Fortaleza, Brazil). The animals used in this study were presumed to be undergoing normal estrous cycles as judged by the presence of normal corpora lutea at the slaughter. Immediately postmortem, the ovaries were washed in $70 \%$ alcohol for $10 \mathrm{~s}$ followed by two washes in Minimal Essential Medium (MEM) supplemented with $100 \mu \mathrm{g} / \mathrm{mL}$ penicillin and $100 \mu \mathrm{g} / \mathrm{mL}$ streptomycin. The pairs of ovaries were transported to the laboratory within $1 \mathrm{~h}$ in MEM at $32^{\circ} \mathrm{C}$.

\subsection{Long-term tissue culture conditions}

The organ culture system used herein was previously described in detail (Matos et al., 2007a). In the laboratory, both ovaries from each animal were stripped of the surrounding fat tissue and ligaments and cut in half. Then the large antral follicles, corpora lutea and medulla were removed. Following this step, the ovarian cortex tissue samples from each ovarian pair were divided into 16 fragments of approximately $3 \times 3 \mathrm{~mm}$ ( $1 \mathrm{~mm}$ thick) in size using a needle 
and scalpel under sterile conditions. The tissue pieces were then randomly selected and either directly fixed for histological and ultrastructural analysis (fresh control) or placed in culture for $1,7,14,21$ or 28 days. Caprine tissues were transferred to 24 -well culture dishes containing 1 $\mathrm{ml}$ of culture media. The culture was performed at $39{ }^{\circ} \mathrm{C}$ in $5 \% \mathrm{CO} 2$ in a humidified incubator, and all of the media were incubated for $1 \mathrm{~h}$ prior to use. The basic culture medium (cultured control) consisted of MEM (pH 7.2-7.4) supplemented with ITS (insulin $6.25 \mu \mathrm{g} / \mathrm{mL}$, transferrin $6.25 \mu \mathrm{g} / \mathrm{mL}$ and selenium $6.25 \mathrm{ng} / \mathrm{mL}$ ), $0.23 \mathrm{mM}$ pyruvate, $2 \mathrm{mM}$ glutamine, $2 \mathrm{mM}$ hypoxanthine, $1.25 \mathrm{mg} / \mathrm{mL}$ bovine serum albumin (BSA), $100 \mu \mathrm{g} / \mathrm{mL}$ penicillin, $100 \mu \mathrm{g} / \mathrm{mL}$ streptomycin (Vetec, Rio de Janeiro, Brazil) and $0.25 \mu \mathrm{g} / \mathrm{mL}$ amphotericin. This medium was called MEM+. For the experimental conditions, the medium was supplemented with either FSH (FSH-2d or FSH-7d, i.e., with replacement of the culture medium every 2 or 7 days, respectively) or a combination of FSH + FGF-2 (with replacement of the culture medium every 2 days). Based on our previous studies with caprine preantral follicle cultures, both substances were used at a concentration of $50 \mathrm{ng} / \mathrm{mL}$ (Matos et al., 2007a and Matos et al., 2007b). In addition, the follicles that were cultured in MEM+ for 7 days were ultrastructurally degenerated; thus we decided to use MEM+ supplemented with FSH as our control medium (Matos et al., 2007a). Moreover, our previous results also have shown that the combination of FSH + FGF-2 promoted a higher percentage of primordial follicle activation (73.5\% for FSH + FGF-2 $\times 57.7 \%$ for FGF-2) and oocyte growth $(50.4 \mu \mathrm{m}$ for FSH + FGF-2 $\times 40.8 \mu \mathrm{m}$ for FGF-2) than the medium supplemented with FGF-2 alone. Additionally, after 7 days of culture, higher percentages of normal follicles were observed only in medium supplemented with FSH (66.7\%) when compared with MEM+ (56.3\% - control medium). Finally, with the increase of the culture period from 1 to 7 days, a decrease in the percentage of normal follicles was observed in all treatments, but not in medium supplemented only with FSH (Matos et al., 2007c). Therefore, we decided to exclude the treatment with FGF-2 only from the present study. Each treatment was repeated four times, using the ovaries of four different animals.

\subsection{Assessment of follicular development and survival}

Before (fresh control) and after 1, 7, 14, 21 or 28 days of culture, all of the pieces were fixed in Carnoy's solution for $12 \mathrm{~h}$ and then dehydrated in increasing concentrations of ethanol. After paraffin embedding (Synth, São Paulo, Brasil), the wax blocks were completely and serially sectioned $(7 \mu \mathrm{m})$, and each section was mounted on glass slides and stained by Periodic Acid Schiff-Hematoxylin. The follicle stage and survival were assessed microscopically 
on serial sections. Coded, anonymized slides were examined with a light microscope (Zeiss, Germany).

The developmental stages of follicles have been defined previously (Silva et al., 2004) as primordial (one layer of flattened granulosa cells around the oocyte) or growing follicles (intermediate: one layer of flattened to cuboidal granulosa cells; primary: one layer of cuboidal granulosa cells; and secondary: two or more layers of cuboidal granulosa cells around the oocyte). The follicles were classified as histologically normal when an intact oocyte was present and surrounded by granulosa cells that were well-organized into one or more layers with no pyknotic nucleus. Atretic follicles were defined as those with a retracted oocyte, pyknotic nucleus, and/or disorganized granulosa cells that were detached from the basement membrane. Overall, 200 follicles were evaluated for each treatment (50 follicles per treatment in one repetition $\times 4$ repetitions $=200$ follicles) .

To evaluate follicular activation, the percentages of histologically normal primordial and growing follicles were calculated before (fresh control) and after culture in each medium. In addition, the follicle and oocyte diameters were measured in healthy follicles only. The oocyte and follicular diameters were measured with the aid of an ocular micrometer. Both diameters, taken from the basement membrane at right angles to each other in the largest cross-section of each growing oocyte and follicle, were measured and averaged. The follicular and oocyte diameters were measured in $\mathbf{2 0}$ follicles for each treatment. Care was taken to count each follicle only once, as has also been done in our earlier studies (Matos et al., 2007a, Matos et al., 2007b and Matos et al., 2007c); thus, only follicles with a visible oocyte nucleus were recorded.

\subsection{Ultrastructural analysis}

Small pieces $(1 \mathrm{~mm} 3)$ of the caprine ovarian tissues were fixed in $2 \%$ paraformaldehyde and $2.5 \%$ glutaraldehyde in $0.1 \mathrm{M}$ sodium cacodylate buffer $(\mathrm{pH} 7.2)$ for $4 \mathrm{~h}$ at room temperature. After fixation, the fragments were post-fixed in $1 \%$ osmium tetroxide, $0.8 \%$ potassium ferricyanide and $5 \mathrm{mM}$ calcium chloride in $0.1 \mathrm{M}$ sodium cacodylate buffer for $1 \mathrm{~h}$. Subsequently, the samples were dehydrated through a gradient of acetone solutions, and the tissues were embedded in Spurr's resin. Semi-thin sections $(3 \mu \mathrm{m})$ were cut on an ultramicrotome (Reichert Supernova, Heidelberg, German) for light microscopy and stained with toluidine blue. Ultra-thin sections $(60-70 \mathrm{~nm})$ were cut on the same ultramicrotome, contrasted with uranyl acetate and lead citrate and examined under a Jeol 1011 (Jeol, Tokyo, 
Japan) transmission electron microscope. Parameters such as the density and integrity of the ooplasmic and granulosa cell organelles, the vacuolization and the basement membrane integrity were evaluated.

\subsection{Statistical analysis}

Data are expressed as the mean \pm SEMs. The percentages of surviving follicles at all stages and the primordial and growing follicles obtained after 1, 7, 14, 21 or 28 days in the various treatments were subjected to arc-sin transformation before an analysis of variance (ANOVA). The data on the primordial and growing follicles, as well as the diameter of the oocytes and follicles, were analyzed by an ANOVA followed by a Fisher's protected least significant difference test (PLSD test) (StatView for Windows, SAS Institute Inc., Cary, NC, USA). Values were considered statistically significant when $\mathrm{P}<0.05$.

\section{Results}

\subsection{Effect of treatments and culture periods on follicle survival}

A total of 3200 follicles were counted to evaluate the follicular morphology, activation and growth of developing follicles. Follicles were observed in both the central and peripheral areas of the cultured fragments. Primordial follicles were the most abundant type found in non-cultured ovarian tissue (fresh control; Fig. 1A). After 7, 14 or 21 days of culture, intermediate follicles were the predominant stage in all treatments (Fig. 1B). Moreover, analysis of the ovarian sections that were cultured with FSH for 28 days revealed the presence of numerous primary (Fig. 1C) and some secondary follicles (Fig. 1D).
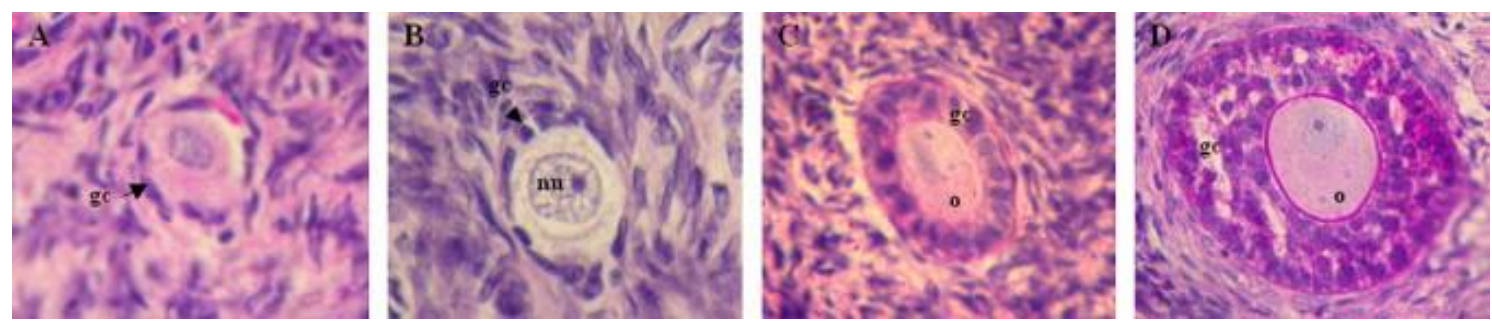

Fig. 1. Histological sections of caprine ovarian tissue, showing normal follicles after staining with Periodic Acid Schiff-Hematoxylin. (A) Primordial follicle from fresh tissue: note the single layer of flattened granulosa cells around the oocyte; $(B)$ intermediate follicles, with the presence of both flattened and cuboidal granulosa cells around the oocyte; (C) primary follicles after 14 days of culture in medium 
containing FSH + FGF-2; and (D) secondary follicles found after 28 days of culture in FSH treatment. o: Oocyte; nu: oocyte nucleus; and gc: granulosa cell (400x).

The effects of the different treatments on follicle survival, i.e., the percentage of histologically normal follicles in the cultured ovarian tissues, is shown in Fig. 2. Except for day 1 , the percentages of histologically normal follicles significantly was decreased $(P<0.05)$ after all culture periods compared to non-cultured follicles (fresh control). After 1 day of culture, there was no significant effect of the treatments on follicle survival $(P>0.05)$. In contrast, after 7 and 21 days of culture, the medium with FSH-7d (with replenishment of the culture medium every 7 days) showed a significantly lower percentage of morphologically normal follicles when compared to the other treatments $(P<0.05)$. Additionally, after $14(63 \%)$ and $28(60.5 \%)$ days, medium supplemented with FSH-2d (with replacement of the culture medium every 2 days) showed higher percentages $(P<0.05)$ of histologically normal follicles than did either $\mathrm{FSH}-7 \mathrm{~d}$ (44.5\%) or the interaction between FSH and FGF-2 (46.5\%).

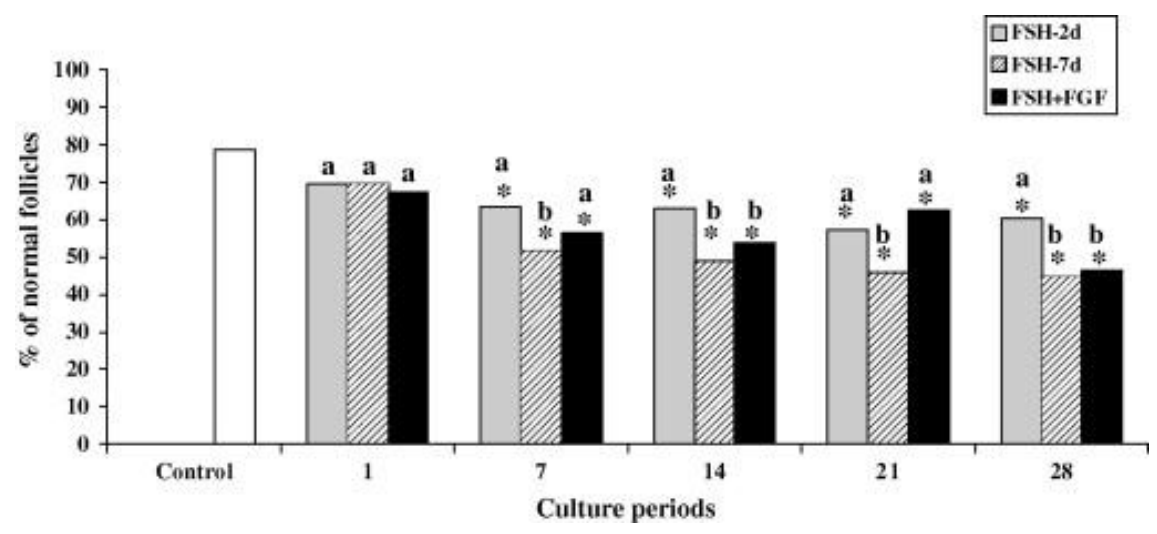

Fig. 2. Percentages (means $\pm \mathrm{SEM}$ ) of histologically normal preantral follicles in fresh tissue (control) and in tissues cultured for 1, 7, 14, 21 or 28 days in medium supplemented with FSH-2d, FSH-7d or FSH + FGF-2. $* \mathrm{P}<0.05$, different from non-cultured ovarian cortex tissue (control/D0). ( $a$ and $b$ ) Different letters denote differences among treatments in the same period $(P<0.05)$.

\subsection{Activation and growth of developing follicles during long-term culture in vitro}

Fig. 3 shows the percentages of the primordial and growing follicles in ovarian cortical tissue before and after culture. In fresh tissues, the percentages of primordial, intermediate, primary and secondary follicles were $76.4 \%, 18.1 \%, 3.0 \%$, and $2.5 \%$, respectively. After culture, in all treatments tested, the percentage of the primordial follicles significantly decreased (Fig. $3 A, P<0.05)$ when compared to the fresh control, as a result of a coincident increase in the proportion of the intermediate follicles ( Fig. 3B, $\mathrm{P}<0.05$ ). With the progression of the culture from day 1 to day 7 (cortical tissues cultured in FSH-7d) and from day 7 to 14 (cortical tissues cultured in FSH-2d), a significant reduction in the primordial follicles ( Fig. $3 A, P<0.05$ ) that was associated with a significant increase in the percentage of the intermediate follicles ( Fig. 
$3 \mathrm{~B}, \mathrm{P}<0.05)$ was observed. In addition, from day 7 to day 14 of culture, only the combination of FSH + FGF significantly increased the proportion of primary follicles $(P<0.05)$. Moreover, after 28 days, significantly more primary follicles were observed in FSH-2d and FSH-7d than in either fresh control or treatment with FSH + FGF-2 ( Fig. 3C, P < 0.05). In contrast, when the comparisons were done among the treatments, there was no significant effect on the percentage of secondary follicles ( Fig. 3D, P > 0.05).

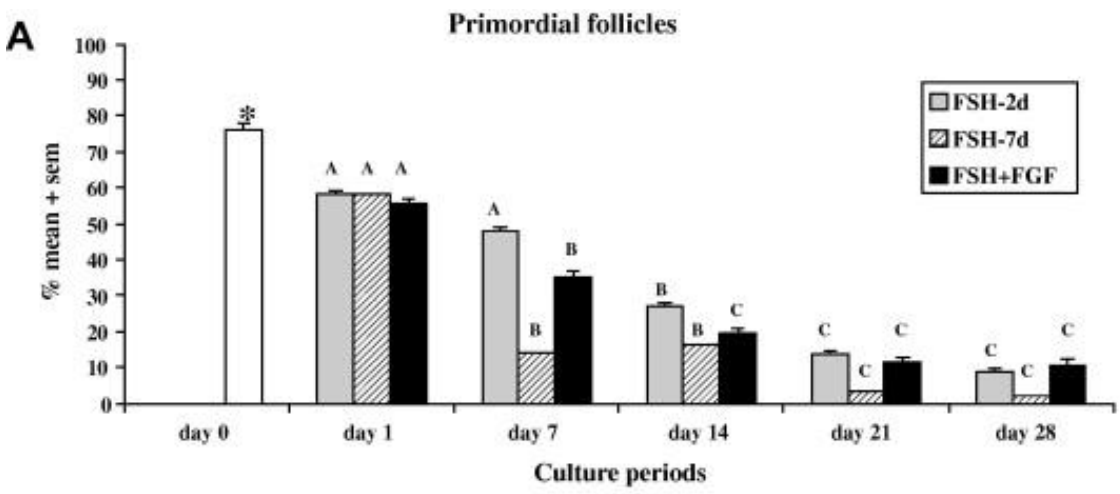

B

Intermediate follicles

ØFSH-7d

EFSH+FGF

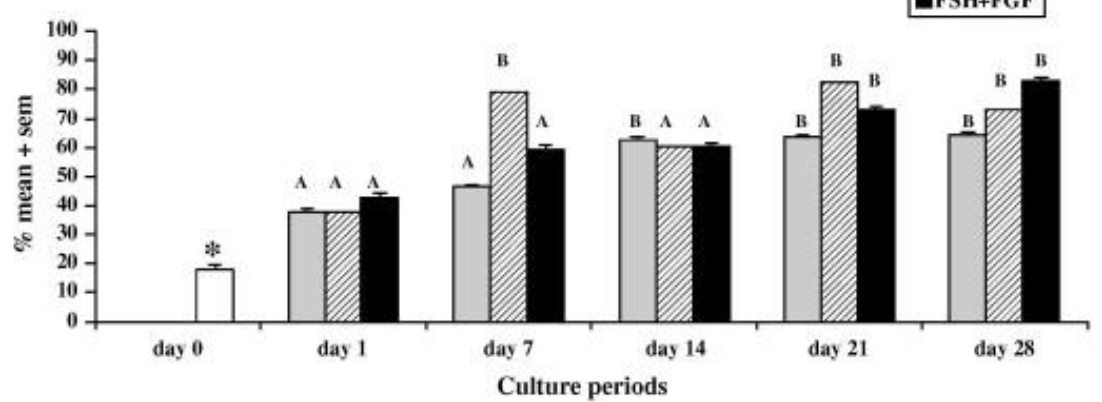

C

Primary follicles

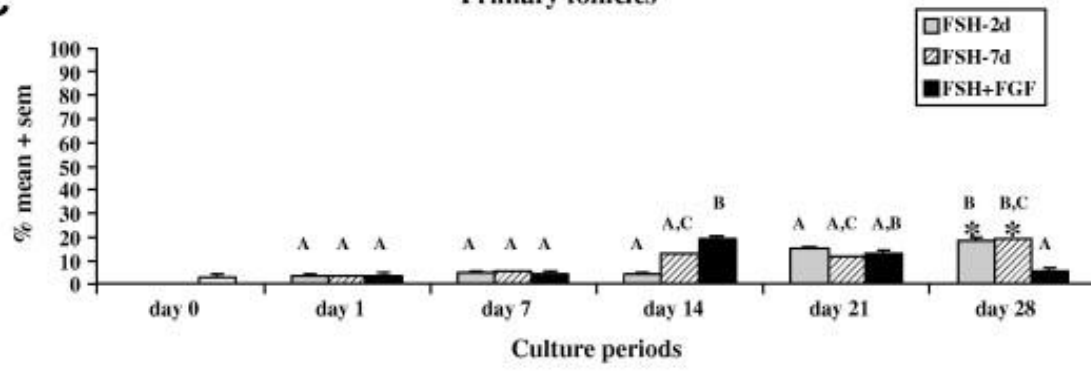

D

Secondary follicles

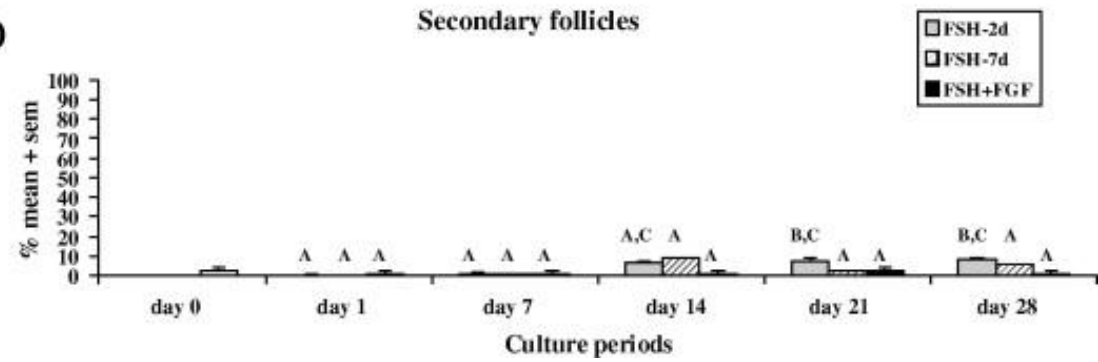

Fig. 3. Percentages (means \pm SEM) of (A) primordial, (B) intermediate, (C) primary, and (D) secondary follicles in non-cultured tissue (control) and in tissue cultured for 1, 7, 14, 21 and 28 days in FSH-2d, FSH$7 \mathrm{~d}$ or FSH + FGF-2. *Different from non-cultured ovarian cortex tissue (fresh control/D0) $(\mathrm{P}<0.05)$. (A and $B$ ) Different letters denote differences between culture periods within the same medium $(P<0.05)$. 
After 28 days, all treatments promoted a significant increase in both oocyte and follicle diameter when compared to fresh controls (Fig. $4 A$ and $B, P<0.05$ ). In addition, at the end of the culture, treatment with FSH-2d showed the highest oocyte and follicle diameters when compared to the other treatments $(P<0.05)$.
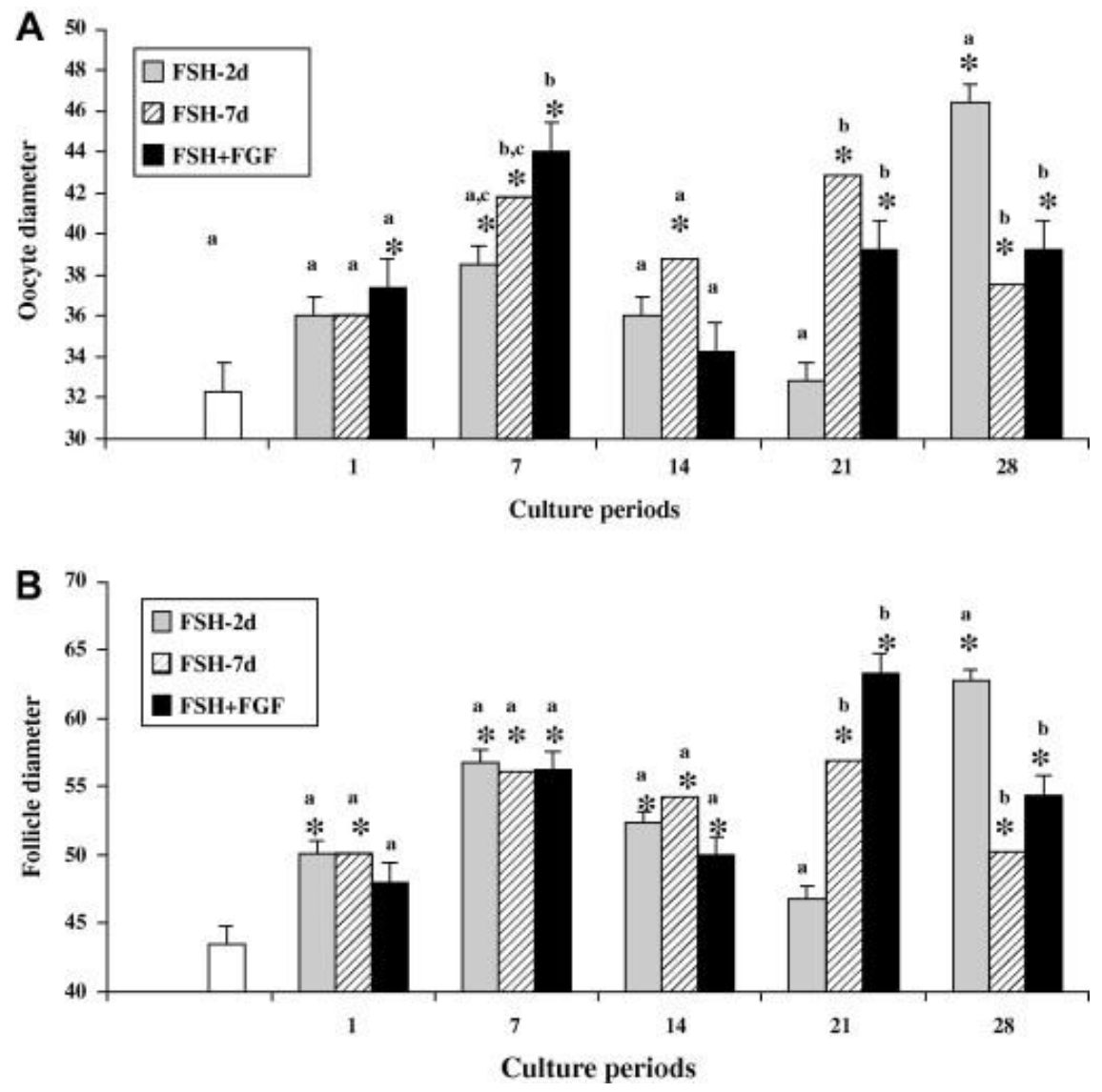

Fig. 4. Mean oocyte (A) and follicle (B) diameter in $\mu \mathrm{m}$ ( \pm SEM) on days $1,7,14,21$ and 28 of in vitro culture.

*Different from non-cultured ovarian cortex tissue (fresh control/DO) $(\mathrm{P}<0.05)$. ( $\mathrm{a}$ and $\mathrm{b})$ Values with different letters denote differences among treatments in the same period $(P<0.05)$.

\subsection{Ultrastructural changes in goat follicles after long-term culture}

TEM studies were performed in ovarian fragments that had been cultured for 1, 7, 14, 21 and 28 days for all treatments, as well as for non-cultured fragments (fresh control). The ultrastructure of the histologically normal follicles from fresh control tissue and from those tissues cultured in FSH (both medium replacement every 2 and 7 days) or in the combination of FSH + FGF-2 for 1 or 7 days appeared quite similar. These follicles exhibited a large oocyte with sparse vesicles spread throughout the ooplasm. Moreover, the homogeneous cytoplasm contained numerous rounded and occasionally elongated mitochondria (Fig. 5A). Golgi complexes were rarely observed. Both smooth and rough endoplasmic reticula were present, either as isolated aggregations or as complex associations with mitochondria and vesicles. The 
granular chromatin was uniformly distributed throughout the oocyte nucleus, and the nucleolus could generally be observed. In all developmental stages, the granulosa cells were well-organized around the oocyte, with a large nuclear-to-cytoplasm ratio. Their nuclei were irregularly shaped, with loose chromatin in the center and small aggregates of condensed chromatin in the periphery. Well-developed rough endoplasmic reticula and mitochondria were the most evident organelles observed in the granulosa cells (Fig. 5B).
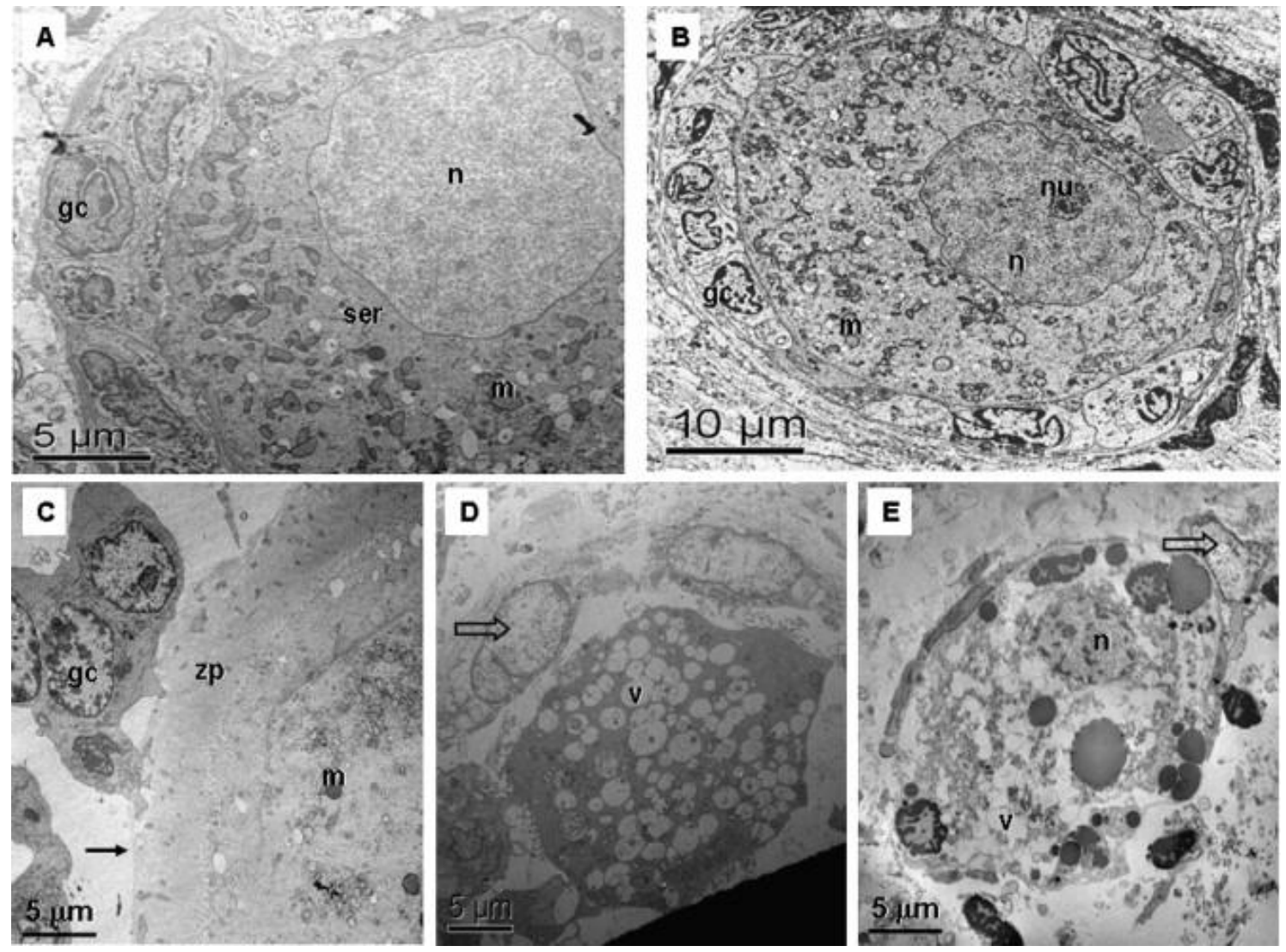

Fig. 5. Electron micrographs of caprine preantral follicles before ( $A$; fresh control; 3240x) and after culture in medium containing FSH-2d for 7 days (B; 3240x), FSH-7d for 14 days (C; 5200x), FSH + FGF-2 for 14 days (D; 3240x) or FSH-2d for 28 days (E; 3240x). After 14 days of culture, note the detachment of the granulosa cells from the basement membrane ( $5 \mathrm{C}$; solid arrow), the extreme vacuolization and the great holes that are present in the cytoplasm, as well as the empty space in the degenerated granulosa cells (5D and E; open arrow) ( $n$ : oocyte nucleus; nu: nucleolus; gc: granulosa cells; m: mitochondria; ser: smooth endoplasmic reticulum; v: vesicles; and zp: zona pelucida).

After 14 days of culture, the TEM studies showed remarkable differences at the ultrastructural level among the treatments. In follicles cultured in FSH-7d, despite the ooplasm and granulosa cells seeming to be well-preserved, a pronounced detachment of the granulosa cells from the zona pellucida was observed (Fig 5C). In addition, when cultured for 14 days in FSH-2d or FSH + FGF-2, follicles had an oocyte with large numbers of vesicles spread throughout the ooplasm and granulosa cells. Signs of damage in the endoplasmic reticulum and mitochondria, as well as a reduction in the number of organelles in both the oocyte and granulosa cells were observed. The oocyte nucleus appeared misshapen and retracted with a 
thin membrane. Furthermore, the granulosa cells showed less contact with each other and exhibited fewer gap junctions (Fig. 5D).

In addition to the progression of the changes described above, the follicles cultured for 21 days in all treatments presented a substantial irregularity of the follicular, oocyte and nuclear outlines. As degeneration progressed, cytoplasmic vacuolation was extremely widespread in all constituents of the granulosa cells and the oocytes, neither of which had clear organelle or membrane definition. Vacuoles were often fused, thus producing a larger vacuolated area, and in most oocytes, the nuclear membrane was broken. Furthermore, some granulosa cells were fragmented or had disappeared, leaving an empty space in the follicular granulosa. Finally, after 28 days, the oocyte, cytoplasmic organelles and outline membranes were no longer identifiable. In addition, the connection between the oocyte and the granulosa cells had disappeared (Fig. 5E).

\section{Discussion}

The present study describes the ultrastructural changes observed in caprine preantral follicles after long-term in vitro culture. It furthermore reports an in vitro effect of FSH alone or in combination with FGF-2 on the activation of primordial follicles and subsequent preantral follicle growth. Additionally, the effects of different frequencies of culture medium replacement (every 2 or 7 days) were evaluated on these same parameters.

After 14 or 28 days of culture, FSH (with replacement of the medium every 2 days) appeared to maintain preantral follicle survival, based on histological analysis, whereas the follicular ultrastructure was negatively affected. In contrast, the other treatments (FSH-7d and FSH + FGF-2) were effective in maintaining follicle ultrastructural integrity up to day 7. Our light histological results confirm earlier studies in which FSH maintained preantral follicle viability after short (Matos et al., 2007a and Matos et al., 2007c) or long-term culture (Cortvrindt et al., 1997, Wright et al., 1999 and Gutierrez et al., 2000). It is suggested that the absence of FSH in the medium could compromise the diffusion of several essential chemical and physical factors through the basement membrane (Hsueh et al., 1994). In contrast to our study, Huamin and Yong (2000) maintained the integrity of isolated caprine primary and secondary follicles for up to 14 days of culture. However, there are some differences in their culture system when compared to ours, especially with regard to the culture medium composition and the highest concentration of FSH used $(100 \mathrm{ng} / \mathrm{ml})$. Furthermore, their positive effects were obtained using light microscopical evaluation of the follicles. 
Nevertheless, several authors have emphasized the importance of TEM studies of follicles after their in vitro culture (Van den Hurk et al., 1998 and Matos et al., 2006). TEM allows for the enhanced evaluation of the actual cell structure, providing information that is not obtained by histology or other analysis. Our current findings therefore confirm this latter view.

The TEM studies presented here revealed obvious differences in the ultrastructural quality of caprine follicles after long-term culture. In all treatments, the follicles cultured for up to 7 days maintained their ultrastructural integrity, while those cultured from day 14 onward showed various signs of degeneration. After 14 days of culture, the proportion of degenerated follicles observed by light microscopy increased when the medium supplemented with FSH was replenished every 7 days. Nevertheless, after TEM analysis, this treatment had more wellpreserved follicles than did others with replacement of the medium every 2 days. It is likely that up to 14 days, follicles cultured with FSH-7d produced paracrine factors in addition to the medium components, which stimulated the maintenance of follicular integrity. In addition, after culture for 3 or 4 weeks, we could see evidence of alterations in the basement membrane and follicular cell-oocyte interactions, which are crucial for follicular maturation. Furthermore, the follicles showed an extreme ooplasm vacuolization, which is a characteristic sign of degeneration and may represent endoplasmic reticulum swelling (Tassel and Kennedy, 1980 and Silva et al., 2000), altered mitochondrial structure (Fuku et al., 1995), or cellular necrosis (de Bruin et al., 2002). Therefore, despite being a time-consuming and expensive technique, TEM is an important tool for detecting early morphological changes after follicular culturing in vitro. In addition, according to Lopes et al. (2009), follicular atresia changes occur first at the ultrastructural level before being able to be identified by light microscopy.

In the first week of culture, the addition of FSH to the culture medium, without refreshment of this medium, was more efficient than the other methods in promoting follicular activation. In contrast, the higher degeneration observed in this treatment after 7 days could be a consequence of an inappropriate medium supply. It is known that after activation, organelle multiplication and an increase in nutrient uptake occurs. Thus, some follicles could die after activation due to an improper environment for continuing their normal development (Rüsse, 1983). Recently, we have demonstrated that FSH could improve caprine follicular activation (Matos et al., 2007a and Matos et al., 2007c). In addition, Joyce et al. (1999) reported that FSH stimulates Kit ligand mRNA expression in the granulosa cells of preantral follicles, which is essential for the initiation of primordial follicle growth (Parrot and Skinner, 1999).

After 14 days of culture, primary follicle development was stimulated by FSH + FGF-2. However, with an increase of the culture period, this interaction did not promote subsequent 
primary follicle growth. In addition, the percentage of primary follicles increased after 28 days of culture in medium containing FSH, independent of the frequency of medium replenishment. According to Shikone et al. (1992), FSH stimulates the expression of FGF-2 receptors in granulosa cells, which suggests that FSH could enhance the stimulatory effect of FGF-2 on primary follicular growth until 14 days of culture. After 2 weeks of culture, the follicles may have increased their metabolism and consequently their need for additional nutrients in the medium. Thus, the increase in ultrastructural alterations coincident with the higher rates of follicular activation may be due to a nutrient deficiency in the medium. Based on this observation, we suggest that an alteration in the medium nutrients, in the FSH or FGF-2 concentrations, and in the frequency of the medium exchange may be necessary to maintain ultrastructural integrity and promote caprine follicle development during long-term culture.

Although an increase in oocyte and follicular diameter after 28 days of culture with FSH-2d was demonstrated, our TEM findings suggest that this light microscopically observed phenomenon is due to follicular necrosis, characterized by cell swelling as a result of increased cellular vacuolization (Barros et al., 2001). As there are FSH receptors in the granulosa cells of early follicles, it is possible that FSH may promote follicular growth and development (Méduri et al., 2002). Previous observations have showed that FSH promotes an increase in both oocyte (Itoh et al., 2002) and follicular diameter (Wright et al., 1999) after long-term culture.

In conclusion, culturing tissue for up to 7 days in medium containing FSH alone or in combination with FGF-2 maintains caprine preantral follicle integrity and promotes their growth in vitro. The culture system described in our study was very efficient for promoting the transition from primordial to primary follicles. However, these conditions did not support the ultrastructural morphology of follicles after long-term culture. These findings show that a morpho-functional analysis by TEM allows a marked improvement in the evaluation of the integrity of caprine ovarian tissue. More studies are necessary to determine the appropriate culture system conditions to promote primordial follicle activation, further growth and the maturation of caprine oocytes by preserving their ultrastructural integrity.

\section{Conflict of interest statement}

The authors declare that there is no conflict of interest that could be perceived as prejudicing the impartiality of the research reported.

\section{Acknowledgements}

This work was supported by CNPq, FINEP and Fundação Cearense de Apoio à Pesquisa (FUNCAP). Maria Helena Tavares de Matos is a recipient of a grant from CNPq (Brazil). We 
would like to acknowledge the generous donation of pFSH by Dr. Jean-François Beckers of the University of Liège, Belgium.

\section{References}

Asakai, R., Tamura, K., Eishi, Y., Iwamoto, M., Kato, Y., Okamo, R., 1993. Basic fibroblast growth factor (bFGF) receptors decrease with luteal age in rat ovarian luteal cells: colocalization of bFGF receptors and bFGF in luteal cells. Endocrinology 133, 1074-1084.

Baird, A., Esch, F., Normède, P., Ueno, N., Ling, N., Boleen, P., Ying, S.Y., Wehrenberg, W.B., Guillemin, R., 1986. Molecular characterization of fibroblast growth factor: distribution and biological activities in various tissues. Recent Progress in Hormone Research 42, 143-205.

Barros, L.F., Hermosilla, T., Castro, J., 2001. Necrotic volume increase and the early physiology of necrosis. Comparative Biochemistry and Physiology 130, 401-409.

Ben-Haroush, A., Abir, R., Ao, A., Jin, S., Kessler-Icekson, G., Feldberg, D., Fisch, B.,2005. Expression of basic fibroblast growth factor and its receptors in human ovarian follicles from adults and fetuses. Fertility and Sterility 84, 1257-1268.

Cortvrindt, R., Smitz, J., Van Steirteghem, A.C., 1997. Assessment of the need for follicle stimulating hormone in early preantral mouse follicle culture in vitro. Human Reproduction 12 , 759-768.

de Bruin, J.P., Dorland, M., Spek, E.R., Posthuma, G., van Haaften, M., Looman, C.W., te Velde, E.R., 2002. Ultrastructure of the resting ovarian follicle pool in healthy young women. Biology of Reproduction 66, 1151-1160.

Fortune, J.E., 2003. The early stages of follicular development: activation of primordial follicles and growth of preantral follicles. Animal Reproduction Science 78, 135-163.

Fuku, E., Xia, L., Downey, B.R., 1995. Ultrastructural changes in bovine oocytes cryopreserved by vitrification. Cryobiology 32, 139-156.

Gospodarowicz, D., Neufeld, G., Schewigerer, L., 1986. Molecular and biological characterization of fibroblast growth factor: an angiogenic factor which controls the proliferation and differentiation of mesoderm and neuro ectoderm derived cells. Cell Differentiation 19, 1-14.

Gougeon, A., 1996. Regulation of ovarian follicular development in primates: facts and hypotheses. Endocrine Reviews 17, 121-155.

Gupta, P.S.P., Ramesh, H.S., Manjunatha, B.M., Nandi, S., Ravindra, J.P., 2008. Production of buffalo embryos using oocytes from in vitro grown preantral follicles. Zygote 16, 57-63.

Gutierrez, C.G., Ralph, J.H., Telfer, E.E., Wilmut, I., Webb, R., 2000. Growth and antrum formation of bovine preantral follicles in long-term culture in vitro. Biology of Reproduction 62, $1322-1328$.

Hsueh, A.J., Billig, H., Tsafriri, A., 1994. Ovarian follicle atresia: a hormonally 
controlled apoptotic process. Endocrine Reviews 15, 707-724.

Huamin, Z., Yong, Z., 2000. In vitro development of caprine ovarian preantral follicles. Theriogenology 54, 641-650.

Itoh, T., Kacchi, M., Abe, H., Sendai, Y., Hoshi, H., 2002. Growth, antrum formation, and estradiol production of bovine preantral follicles cultured in a serum-free medium. Biology of Reproduction 67, 1099-1105.

Joyce, I.M., Pendola, F.L., Wigglesworth, K., Eppig, J.J., 1999. Oocyte regulation of Kit ligand expression in mouse ovarian follicles. Developmental Biology 214, 342-353.

Lopes, C.A.P., Santos, R.R., Celestino, J.J.H., Melo, M.A., Chaves, R.N., Campello, C.C., Silva, J.R., Báo, S.N., Jewgenow, K., Figueiredo, J.R., 2009. Short-term preservation of canine preantral follicles: effects of temperature, medium and time. Animal Reproduction Science 115, 201214.

Matos, M.H.T., van den Hurk, R., Martins, F.S., Santos, R.R., Luque, M.C.A., Silva, J.R.V., Celestino, J.J.H., Báo, S.N., Figueiredo, R.R., 2006. Histological and ultrastructural features of caprine preantral follicles after in vitro culture in the presence of absence of índole-3-acetic acid. Animal Reproduction 3, 415-422.

Matos, M.H.T., Lima-Verde, I.B., Luque, M.C.A., Maia Jr., J.E., Silva, J.R.V., Celestino, J.J.H., Martins, F.S., Báo, S.N., Lucci, C.M., Figueiredo, J.R., 2007a. Essential role of follicle stimulating hormone in the maintenance of caprine preantral follicle viability in vitro. Zygote 15, 173-182.

Matos, M.H.T., van den Hurk, R., Lima-Verde, I.B., Luque, M.C.A., Santos, K.D.B., Martins, F.S., Báo, S.N., Lucci, C.M., Figueiredo, J.R., 2007b. Effects of fibroblast growth factor-2 on the in vitro culture of caprine preantral follicles. Cells, Tissues, Organs 186, 112-120.

Matos, M.H.T., Lima-Verde, I.B., Bruno, J.B., Lopes, C.A.P., Martins, F.S., Santos, K.D.B., Rocha, R.M.P., Silva, J.R.V., Báo, S.N., Figueiredo, J.R., 2007c. Follicle stimulating hormone and fibroblast growth factor- 2 interact and promote goat primordial follicle development in vitro. Reproduction, Fertility and Development 19, 677-684.

McGee, E., Spears, N., Minami, S., Hsu, S.-Y., Chun, S.-Y., Billig, H., Hsueh, A.J.W., 1997. Preantral ovarian follicles in serum-free culture: suppression of apoptosis after activation of the cyclic guanosine 30-50 -monophosphate pathway and stimulation of growth and differentiation by follicle-stimulating hormone. Endocrinology 138, 2417-2424.

Méduri, G., Charnaux, N., Driancourt, M.-A., Combettes, L., Granet, P., Vannier, B., Loosfelt, H., Migrom, E., 2002. Follicle-stimulating hormone receptors in oocytes? Journal of Clinical Endocrinology and Metabolism 87, 2266-2276.

Mitchell, L.M., Kennedy, C.R., Hartshorne, G.M., 2002. Effects of varying gonadotrophin dose and timing on antrum formation and ovulation efficiency of mouse follicles in vitro. Human Reproduction 17, 1181-1188.

Muruvi, W., Picton, H.M., Rodway, R.G., Joyce, I.M., 2005. In vitro growth of oocytes from primordial follicles isolated from frozen-thawed lamb ovaries. Theriogenology 64, 1357-1370. 
Nilsson, E., Parrot, J.A., Skinner, M.K., 2001. Basic fibroblast growth factor induces primordial follicle development and initiates folliculogenesis. Molecular and Cellular Endocrinology 175, 123-130.

Oktay, K., Briggs, D., Gosden, R.G., 1997. Ontogeny of follicle-stimulating hormone receptor gene expression in solated human ovarian follicles. Journal of Clinical Endocrinology and Metabolism 82, 3748-3751.

O'Shaughnessy, P.J., Dudley, K., Rajapaksha, W.R., 1996. Expression of follicle stimulating hormone-receptor mRNA during gonadal development. Molecular and Cellular Endocrinology 125, 169-175.

Otala, M., Erkkilä, K., Tuuri, T., Sjöberg, J., Suomalainen, L., Suikkari, A.M., Pentikäinen, V., Dunkel, L., 2002. Cell death and its suppression in human ovarian tissue culture. Molecular Human Reproduction 8, 228-236.

Parrot, J.A., Skinner, M.K., 1999. Kit-ligand/stem cell factor induces primordial follicle development and initiates folliculogenesis. Endocrinology 140, 4262-4271.

Roy, S.K., Treacy, B.J., 1993. Isolation and long-term culture of human preantral follicles. Fertility and Sterility 59, 783-790.

Rüsse, I., 1983. Oogenesis in cattle and sheep. Bibliotheca Anatomica 24, 77-92.

Sadeu, J.C., Cortvrindt, R., Ron-El, R., Kasterstein, E., Smitz, J., 2006. Morphological and ultrastructural evaluation of cultured frozen-thawed human fetal ovarian tissue. Fertility and Sterility 85, 1130-1141.

Shikone, T., Yamoto, M., Nakano, R., 1992. Follicle-stimulating hormone induces functional receptors for basic fibroblast growth factor in rat granulosa cells. Endocrinology 131, 1063 1068.

Silva, J.R.V., Lucci, C.M., Carvalho, F.C.A., Báo, S.N., Costa, S.H.F., Santos, R.R., Figueiredo, J.R., 2000. Effect of coconut water and Braun-Collins solutions at different temperatures and incubation times on the morphology of goat preantral follicles preserved in vitro. Theriogenology 54, 809-822.

Silva, J.R.V., van den Hurk, R., Matos, M.H.T., Santos, R.R., Pessoa, C., Moraes, M.O., Figueiredo, J.R., 2004. Influences of FSH and EGF on primordial follicles during in vitro culture of caprine ovarian cortical tissue. Theriogenology 61, 1691-1704.

Tassel, R., Kennedy, J.P., 1980. Early follicular development and atretic changes in the ovary of the lamb - fine structure and histochemistry. Australian Journal of Biological Sciences 33, 675687.

van den Hurk, R., Zhao, J., 2005. Formation of mammalian oocytes and their growth, differentiation and maturation within ovarian follicles. Theriogenology 63, 1717-1751.

van den Hurk, R., Spek, E.R., Hage, W.J., Fair, T., Ralph, J.H., Schotanus, K., 1998.Ultrastructure and viability of isolated bovine preantral follicles. Human Reproduction 4, 833-841. 
Wandji, S.-A., Fortier, M.A., Sirard, M., 1992. Differential response to gonadotrophins and prostaglandin E2 in ovarian tissue during prenatal and postnatal development in cattle. Biology of Reproduction 46, 1034-1041.

Wandji, S.-A., Eppig, J.J., Fortune, J.E., 1995. FSH and growth factors affect the growth and endocrine function in vitro of granulosa cells of bovine preantral follicles. Theriogenology 45 , 817-832.

Wandji, S.-A., Srsen, V., Voss, A.K., Eppig, J.J., Fortune, J.E., 1996. Initiation in vitro of growth of bovine primordial follicles. Biology of Reproduction 55, 942-948.

Wright, C.S., Hovatta, O., Margara, R., Trew, G., Winston, R.M.L., Franks, S., Hardy, K., 1999. Effects of follicle-stimulating hormone and serum substitution on the invitro growth of human ovarian follicles. Human Reproduction 14, 1555-1562. 